\title{
The Two Way Shape Memory Effect in Stabilized Cu-Zn-Al Single and Polycrystals
}

\author{
P. Arneodo Larochette, E. Cingolani, A. Yawny and M. Ahlers \\ Centro Atómico Bariloche, Comisión Nacional de Energía Atómica, 8400 S.C. de Bariloche, Argentina
}

\begin{abstract}
The influence of martensite stabilization on the two way shape memory effect (TWME) has been studied in a commercial $\mathrm{Cu}-\mathrm{Zn}-\mathrm{Al}$ alloy. It is shown that the TWME is never complete, in contrast to results for single crystals. It depends on the fraction of martensite that is stabilized, i.e. on the stabilization stress and on the temperature to which the sample is heated after stabilization: The lower the stress, the higher is the efficiency of the TWME, but the smaller is also the total TWME strain. No influence of heating velocity could be detected up to $140^{\circ} \mathrm{C}$.
\end{abstract}

\section{INTRODUCTION}

The two way shape memory effect (TWME) is generally obtained by a training process, which consists either of a temperature cycling through the transformation at a fixed stress, or of a stress cycling through the transformation at constant temperature, or of a combination of both. It has been shown, however [1] that in single crystals a complete TWME can also be induced if the martensite is aged and then retransformed to the $\beta$ phase on heating, provided the temperature is above $0{ }^{\circ} \mathrm{C}$ in order to have diffusion [2]. Apparently, after retransforming the bulk martensite to the $\beta$ phase some martensite nuclei are retained and stabilized, which then cause the retransformation to the preferred variant on cooling.

The question that has remained open is whether and to what extent diffusional processes in the martensite can lead to a TWME also in polycrystals. Experiments have now been performed using a commercial alloy, and the results are reported in this paper.

\section{EXPERIMENTAL TECHNIQUES AND RESULTS}

The samples were obtained from a commercial wire, produced by AMT of Belgium. The composition was $73.43 \mathrm{wt} \% \mathrm{Cu}, 19.92 \mathrm{wt} \% \mathrm{Zn}, 6.3 \mathrm{wt} \% \mathrm{Al}$ and $0.35 \mathrm{wt} \% \mathrm{~B}$. The $\mathrm{B}$ was added as a grain refiner, it is practically insoluble in the alloy. The composition in atomic \% of the $\mathrm{Cu}-\mathrm{Zn}$ - $\mathrm{Al}$ phase therefore was 68.23 at $\% \mathrm{Cu}, 17.99 \mathrm{at} \% \mathrm{Zn}$ and 13.78 at $\% \mathrm{Al}$ with $\mathrm{e} / \mathrm{a}=1.456$. The measured $\mathrm{Ms}$ temperature oscillated between $28{ }^{\circ} \mathrm{C}$ and $30{ }^{\circ} \mathrm{C}$, in good agreement with that for single crystals of the same composition $\left(\mathrm{Ms}=22^{\circ} \mathrm{C}\right)$ [3]. The grain size was 0.3 to $0.8 \mathrm{~mm}$.

From the wire of $3 \mathrm{~mm}$ diameter samples of $70 \mathrm{~mm}$ length were cut. They were homogenized at 800 ${ }^{\circ} \mathrm{C}$ for $30 \mathrm{~min}$. and then air cooled to room temperature into the martensitic state. The $\beta$ phase was sufficiently stable so that on cooling no decomposition was expected. Indeed, samples that were quenched 
from $800^{\circ} \mathrm{C}$ into water at room temperature for comparison showed the same $\mathrm{Ms}$ temperature. The main reason for the slow cooling was that after quenching the polycrystals fractured at quite low stresses. A few crystals were also quenched from $800^{\circ} \mathrm{C}$ to $60^{\circ} \mathrm{C}$, in order to compare with the results in single crystals. The $70 \mathrm{~mm}$ long samples were then heated to $\mathrm{T}_{\text {sta }}=50{ }^{\circ} \mathrm{C}$, thus retransforming to the $\beta$ phase. The martensite was induced by stressing the sample in tension to a maximum stress $\sigma_{\text {sta }}$. At this stress it was aged for a time $t_{\text {sta }}$ generally of $90 \mathrm{~min}$, and then unloaded. Due to the stabilization some martensite was retained, corresponding to a strain $\varepsilon_{\text {sta }}$. On cooling to room temperature the whole sample transformed to the martensitic phase. It was made sure that while stress inducing the martensite no irreversible plastic deformation occurred, by establishing that the sample length after a heating to $800{ }^{\circ} \mathrm{C}$, i.e. after retransforming all to the $\beta$ phase, had not changed compared to the original one before the tensile testing, at least within the precision of the measurement.

In figure 1 a typical stress - strain curve is shown. Changes in the sample length were measured by an attached extensometer. It can be noted that the tensile stress increased strongly with strain. Stresses above $300 \mathrm{MPa}$ generally led to fracture. Whereas in single crystals the transformation stress is quite independent of the fraction transformed, in the polycrystals it has to be taken as an additional parameter. On it depends for example the retained strain $\varepsilon_{\text {sta }}$ after stabilization and unloading, as seen in figure 2: The ratio $\varepsilon_{s a} / \varepsilon_{\max }$ starts to be appreciable for stresses above the transformation stress $\left(\sigma_{\beta \rightarrow M}\right)$ and increases with $\sigma_{\text {sta }}$, but remains below unity. A few samples, instead of being air cooled, were water quenched from 800 ${ }^{\circ} \mathrm{C}$ to $60^{\circ} \mathrm{C}$, and then after the required preparation, which lasted less than ten minutes, deformed in tension in order to stress induce the martensite. In figure 2 the results for these samples are added. Since they fractured already at low stressed this treatment was abandoned.

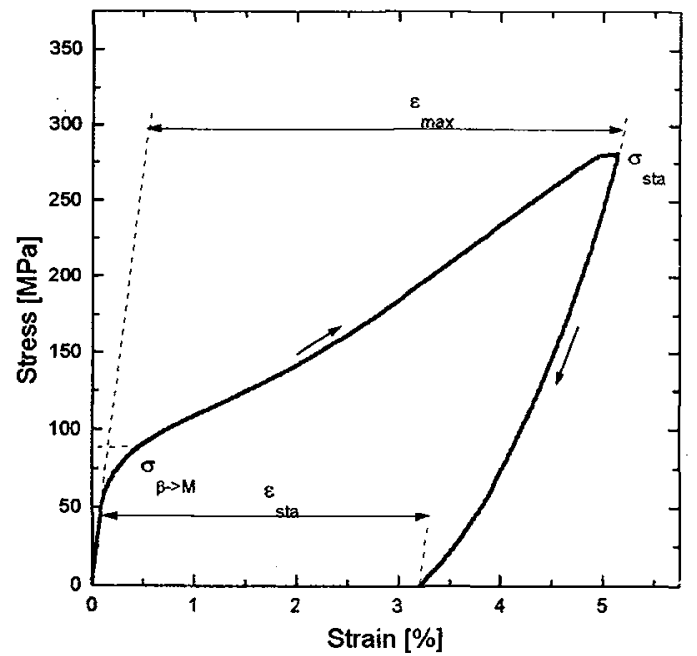

Figure 1: Typical stabilization cycle: The martensite is stress induced at $50^{\circ} \mathrm{C}>$ Af to $\sigma_{\text {sta }}$, stabilized for a time $\mathrm{t}_{\text {sta, }}$ unloaded at $50{ }^{\circ} \mathrm{C}$ with strain $\varepsilon_{\text {sta }}$ due to retained martensite.

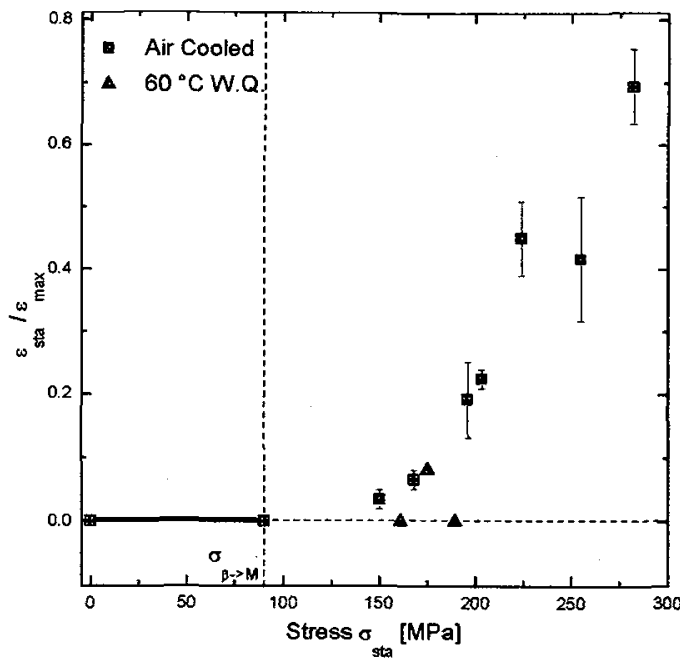

Figure 2: Ratio of retained to total stress induced martensite, as a function of maximum stabilizing stress $\sigma_{s t a}$. For stresses below $\sigma_{\beta \rightarrow M} \approx 90 \mathrm{MPa}$ the ratio is strictly 0 . Each point represents a different sample, and the symbols distinguish the heat treatments, air cooled or quenched into water at $60^{\circ} \mathrm{C}\left(60^{\circ} \mathrm{C} \mathrm{W.Q.)}\right.$

In order to analyze the TWME of the stress induced and stabilized samples of $70 \mathrm{~mm}$ length, the center part was cut into three samples of $11 \mathrm{~mm}$ length each, inserted into a dilatometer and the length 
changes registered during heating and cooling cycles. One of the three samples was heated to $140^{\circ} \mathrm{C}$ at a velocity of $0.5^{\circ} \mathrm{C} / \mathrm{min}$, then cooled at $2{ }^{\circ} \mathrm{C} / \mathrm{min}$, followed by a few heating and cooling cycles between -5 ${ }^{\circ} \mathrm{C}$ and $95^{\circ} \mathrm{C}$. The second sample was treated in the same way, except that the initial heating velocity to $140^{\circ} \mathrm{C}$ was much faster, $600^{\circ} \mathrm{C} / \mathrm{min}$. The heating velocity has a strong influence in single crystals [4], and this experiment served to evaluate the influence in polycrystals. The third sample was heated to a lower intermediate temperature with $0.5^{\circ} \mathrm{C} / \mathrm{min}$, followed by a cooling and reheating to a somewhat higher temperature as before, thus reaching finally $140^{\circ} \mathrm{C}$ after several repeated cycles.

In figure 3 is shown the result for the sample that was heated at $0.5^{\circ} \mathrm{C} / \mathrm{min}$ to $140^{\circ} \mathrm{C}$, then cooled to $-10^{\circ} \mathrm{C}$ and reheated to $100^{\circ} \mathrm{C}$, and the same cycle repeated once more. It can be noted that the sample contraction starts clearly below $50^{\circ} \mathrm{C}$, the stabilization temperature. It is apparently due to the martensite which had disappeared on unloading at $50^{\circ} \mathrm{C}$, but had transformed again to the original variant during cooling to room temperature, since otherwise no length change on reheating would have been observed below this temperature. Above $\mathrm{T}_{\text {sta }}=50{ }^{\circ} \mathrm{C}$ then the retained martensite of strain $\varepsilon_{\text {sta }}$ retransforms (stage II). Therefore the total retransformation strain $\varepsilon_{\text {total }}$ must be larger than $\varepsilon_{\text {sta }}$, and at or below the total strain $\varepsilon_{\max }$ for the stress induced martensite. In figure 4 the ratio $\varepsilon_{\text {total }} / \varepsilon_{\text {sta }}$ as a function of $\sigma_{\text {sta }}$ is shown for the alloys studied: It can be noted that the higher the maximum stress, the smaller is the contribution of the martensite that had retransformed on unloading. Apparently stabilizing at low stresses create favorable configurations such that a reduced amount of stabilized nuclei grow to a large extent. With increasing stress it gets more and more difficult to create these configurations which can act as nuclei for martensite on cooling.

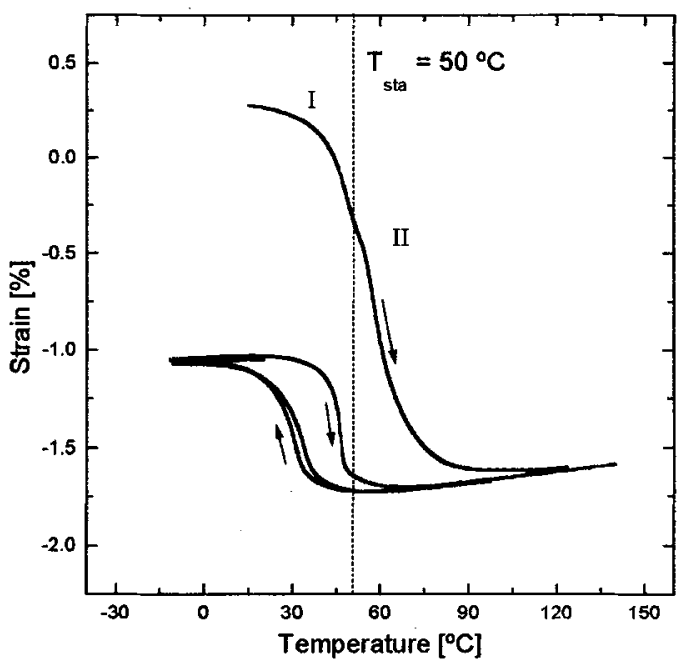

Figure 3: A sample aged at $50{ }^{\circ} \mathrm{C}$ at a stress of $255 \mathrm{MPa}$, then unloaded and cooled to room temperature is heated in the dilatometer. First heating leads to sample shrinkage in steps I and II. The heating to $140{ }^{\circ} \mathrm{C}$ with velocity of $0.5^{\circ} \mathrm{C} / \mathrm{min}$ and subsequent cooling is indicated by arrows. The dilatation strain is referred to the total sample length. Note that a second cycle heated below $140^{\circ} \mathrm{C}$ superimpose on cooling with the first one.

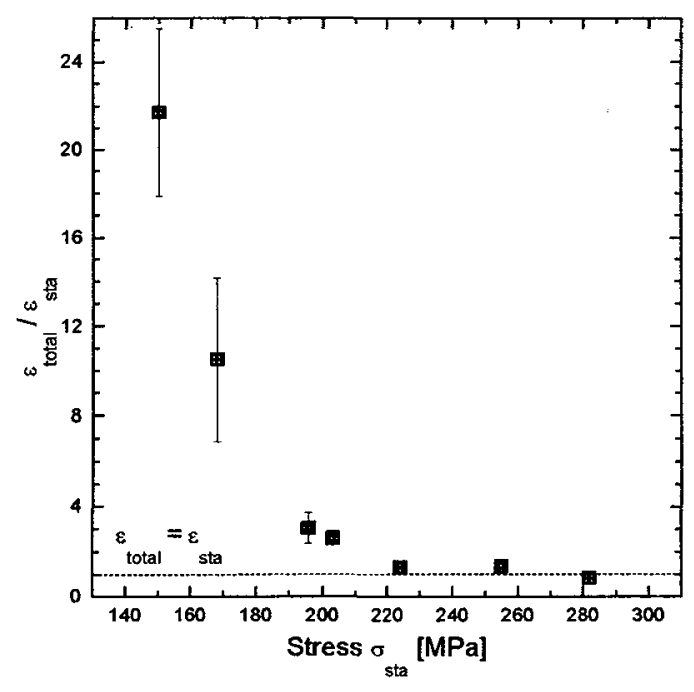

Figure 4: The ratio of the total retransformation strain $\varepsilon_{\text {total }}$ and the strain $\varepsilon_{\text {sta }}$ retained after unloading the stabilized sample, versus the stablization stress. 
Instead of heating continously to $140^{\circ} \mathrm{C}$, the third sample of the set cut from a single tensile deformed piece was heated to a temperature below $140^{\circ} \mathrm{C}$, at which not all material had retransformed to the $\beta$ phase, and on cooling the efficiency of the TWME was measured. In figure 5 the set of cycles going to higher and higher temperatures is illustrated. Take the n-th cycle: previously the sample had been cooled to $\mathrm{T}_{\mathrm{n}}^{\min }=-10^{\circ} \mathrm{C}$, and all had transformed to martensite. On heating to $\mathrm{T}_{\mathrm{n}}^{\max }$ the sample transformed partially to the $\beta$ phase, and from the dilatation curve a strain $\varepsilon_{n}^{\beta}$ (with respect to the sample length) is obtained. On cooling the sample elongates and leads to a strain at $-10^{\circ} \mathrm{C}$. In figure 5 the strains $\varepsilon_{\mathrm{n}}^{\mathrm{M}}$ and $\varepsilon_{\mathrm{n}}^{\beta}$ are defined. In figure 6 has been drawn the ratio $\varepsilon_{n}^{M} / \varepsilon_{n}^{\beta} \equiv \eta_{\mathrm{n}}$ as a function of the maximum reached temperature $T_{n}^{\max }$ in the $n$-th cycle, for several stabilization stresses $\sigma_{\text {sta }}$, which are given in the figure. In the same figure are also added the results when the sample is heated in one step to about $140{ }^{\circ} \mathrm{C}$ with the same heating velocity of $0.5^{\circ} \mathrm{C} / \mathrm{min}$. Comparing both sets it can be concluded that it makes no difference whether the sample is heated in one or in several steps, the ratio $\eta_{\mathrm{n}}$ is only a function of the maximum reached temperature. This is also confirmed by the observation that repeated cycling to the same temperature keeps the ratio $\eta_{\mathrm{n}}$ constant, as noted in figure 3 . For maximum reached temperatures below $60{ }^{\circ} \mathrm{C}$ the ratio $\eta_{\mathrm{n}}$ changes little, similar to what has been observed in single crystals, see fig 6 in ref [1]. Figure 6 shows that the maximum applied stress is an important variable. This is clearly seen in figure 7, in which $\eta_{\mathrm{n}}$ is plotted versus $\sigma_{\text {sta }}$ at $140{ }^{\circ} \mathrm{C}$ for both sets, the sample heated in steps and heated directly: With decreasing $\sigma_{\text {sta }}$ the efficiency $\eta$ at $140^{\circ} \mathrm{C}$ increases. In order to check whether the deterioration of

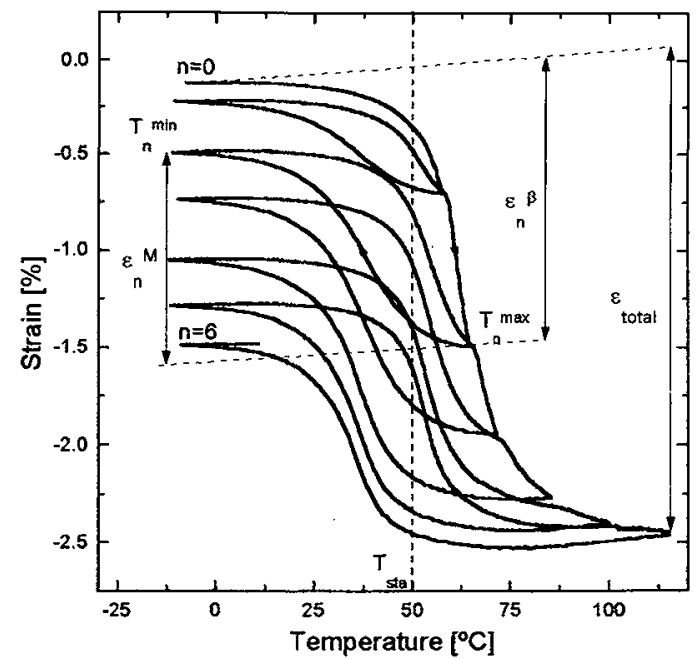

Figure 5: Succesive heating and cooling cycles, starting the heating at $n=0$. The relevant quantities are defined in the figure. The strain is referred to the sample length.

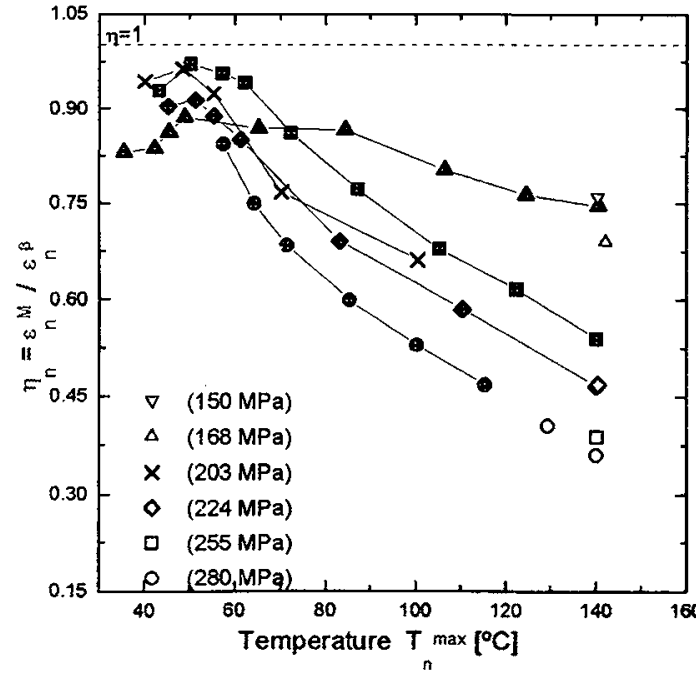

Figure 6: The ratio $\varepsilon_{n}^{M} / \varepsilon_{n}^{\beta} \equiv \eta_{\mathrm{n}}$, defined in figure 5 is plotted as a function of the maximum reached temperature in the $\mathrm{n}$-th cycle for different stabilizing stresses (full symbols). Also are shown the results for the one step heating to $140^{\circ} \mathrm{C}$ at $0.5^{\circ} \mathrm{C} / \mathrm{min}$ (open symbols).

$\eta$ with increasing temperature is due to a recovery effect, the results are compared with those obtained from the samples that were heated with the higher velocity of $600{ }^{\circ} \mathrm{C} / \mathrm{min}$. The data are also shown in figure 7: Within the experimental uncertainty no influence of the heating velocity is seen.

The maximum reached stress $\sigma_{\text {sta }}$, which determines the martensite strain $\varepsilon_{\max }$ is an important variable, in contrast to the results for the single crystals. It determines the retained martensite on unloading 
(figure 2), and also how much martensite of the stress induced variant forms after cooling to room temperature, which then leads to the retransformation strain $\varepsilon_{\text {total }}$ (figure 5) during the first heating cycle to $140^{\circ} \mathrm{C}$. The ratio $\varepsilon_{\text {total }}$ to the total stress induced transformation strain $\varepsilon_{\max }$ (figure 1) is shown in figure 8: This ratio is quite constant for stresses above $200 \mathrm{MPa}$, but seems to increase when the stress is lowered. The continuous curve has been drawn with the assumption that the ratio goes to 1.0 at the yield stress $\sigma_{\beta \rightarrow M}$ when the transformation starts. An argument for this possibility, which is not justified by the data points alone, is given below.

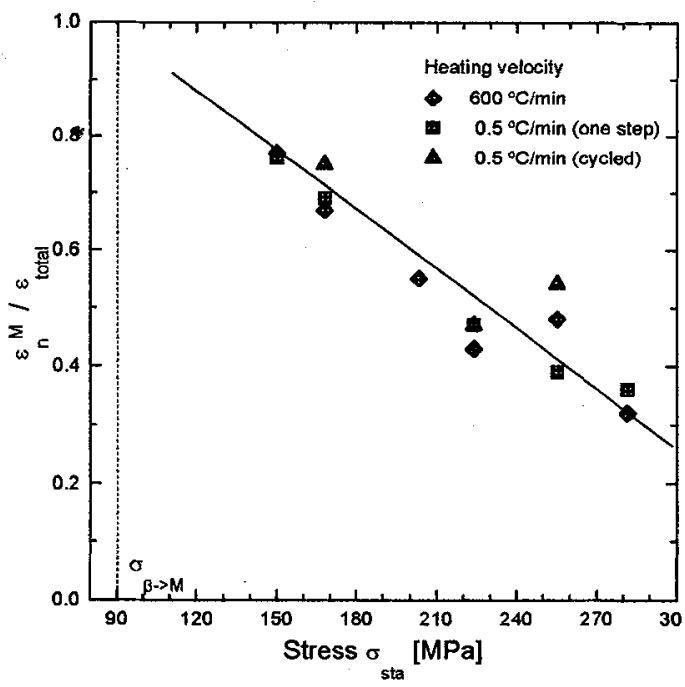

Figure 7: The efficiency $\eta \equiv \varepsilon_{n}^{M} / \varepsilon_{\text {total }}$ at $140^{\circ} \mathrm{C}$ after heating in several or in one step at a velocity of $0.5^{\circ} \mathrm{C} / \mathrm{min}$, and for rapid heating at $600^{\circ} \mathrm{C} / \mathrm{min}$.

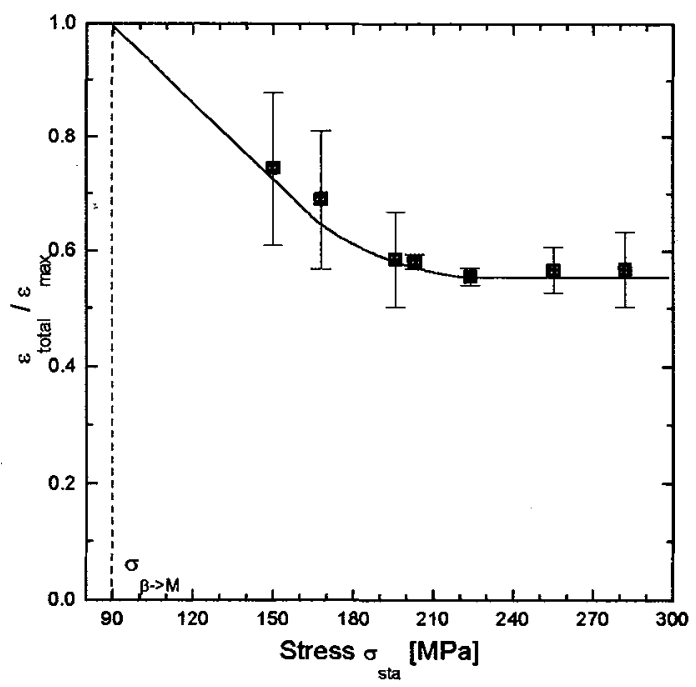

Figure 8: The ratio $\varepsilon_{\text {total }}$ to the total stress induced transformation strain $\varepsilon_{\max }$. The continuous curve is drawn with the assumption that the ratio is 1 at $\sigma_{\beta \rightarrow M}$.

\section{DISCUSSION}

The present results are now compared with those obtained for the single crystals [1,4]. Although the polycrystals are of a different composition and contain $\mathrm{B}$, a comparison is justified.

The single crystals with e/a $=1.48$ had been quenched from $850^{\circ} \mathrm{C}$ to $57^{\circ} \mathrm{C}$, and were transformed at this temperature by tensile stresses [1]. For this reason some polycrystaline samples were also quenched to $60^{\circ} \mathrm{C}$. As shown in figure 2 the fraction of retained martensite on unloading is very small. This contrasts with the single crystal which could be stabilized completely in the martensitic state at $57^{\circ} \mathrm{C}$ [1]. Single crystals which had been air cooled, instead of being quenched, showed the same behavior as the quenched ones.

Although a large fraction of the stress induced martensite retransforms to the $\beta$ phase on unloading the polycrystals, some stabilization must have occured, since on reheating some of the martensite, which had formed on cooling after unloading, retransformed back as the stress induced variant, evidenced from figures 3 and 4.

In the single crystals, the martensite nuclei that are retained in the $\beta$ phase get sufficiently stabilized to remain present even at elevated temperatures far above As, especially when they are permitted to continue stabilizing during a sufficiently slow heating within the $\beta$ phase [4]. In the polycrystals, with the treatment 
described in the text, there must be a spectrum of differently stabilized nuclei. This is evident from figure 6 : The higher the temperature the smaller the density of retained nuclei and the smaller the ratio $\varepsilon_{n}^{M} / \varepsilon_{n}^{\beta}$, whereas repeated cycling which keeps the maximum temperature fixed does not change the efficiency of the TWME (figure 3 as an example). It should be clear that the ratio $\eta_{\mathrm{n}}$ in figure 6 can be identified with the efficiency of the TWME, referred to the total martensite fraction that has been retransformed to the $\beta$ phase at $T_{\mathfrak{n}}^{\max }$

Figures 6 and 7 show that the TWME efficiency at $140{ }^{\circ} \mathrm{C}$ increases with decreasing stress, independent of the heating velocity and whether the heating proceeded in one or several steps. The linear dependence in figure 7 extrapolate to 1 at the stress $\sigma_{\beta \rightarrow M}$ at which martensite starts to be induced, ie it aproaches the same behavior as in the single crystals. This must be related to the existence of the grain boundaries which present obstacles to the propagation of the martensite plates. By reducing the fraction of stabilized martensite, the importance in the interaction with the grain boundaries is diminished, and the polycrystals get closer to the single crystals in efficiency. This rationalizes the observation that the efficiency $\eta$ increases with decreasing stabilization stress and aproaches 1 at the yield stress (figure 7). Following this line of arguments it is well conceivable that the first stress induced martensite plates that form do behave in the same way as in the single crystals, i.e. on retransformation to the $\beta$ phase during unloading a sufficient density of nuclei, as in the single crystals is retained so that on cooling all transforms back to the stress induced variant. With this assumption the continuous line, ending at 1 for $\sigma_{\beta \rightarrow M}$ has been drawn in figure 8 .

The possibility to extrapolate to the single crystal behavior at the critical transformation stress leads to the important question that merits former studies, whether the difference between the behavior in single crystals and polycrystals is due to a smaller concentration of vacancies, which reduces the stabilization of the martensite nuclei, or whether the retention and stabilization of martensite nuclei is impeded by the presence of the grain boundaries, with the martensite variants that form last at the highet stresses leading to the lowest density of retained nuclei after heating to the $\beta$ phase. The latter alternative is suggested but not proved by the present results.

\section{Acknowledgements}

This work was supported partially by the Consejo Nacional de Investigaciones Cientificas y Técnicas of Argentina.

\section{References}

[1] E. Cingolani, M. Ahlers and M. Sade, Acta metall. mater. 43 (1995) 2451.

[2] A. Abu Arab and M. Ahlers, Acta metall. mater. 36 (1988) 2627.

[3] A. Planes, R. Romero and M. Ahlers, Acta metall mater. 38 (1990) 1757

[4] E. Cingolani and M. Ahlers, Scripta metall. mater. 33 (1995) 1375. 